\title{
SOBRE ALGUMAS INTERPRETAÇÓES DAS RELAÇÓES ENTRE A FILOSOFIA OCKHAMIANA E A FÍSICA DOS MODERNOS
}

\author{
Carlos Eduardo de Oliveira ${ }^{I^{*}}$
}

\begin{abstract}
RESUMO: O texto traz uma análise sobre algumas das várias interpretaçôes que defendem a existência de uma relação entre a filosofia moderna e o experimentalismo e a física ockhamianas. Buscando esclarecer alguns dos pressupostos dessas interpretaçóes, o presente artigo sugere apontar alguns de seus limites, visando a uma descrição mais acurada do problema por elas enfrentado.
\end{abstract}

PALAVRAS-CHAVE: Guilherme de Ockham, Física, aristotelismo, Idade Média, Modernidade.

Já se vão quase quinze anos desde que, em meio às celebraçôes do quarto centenário do nascimento de Descartes, em 1996, foi organizado em Paris, pelo "Centro de história das ciências e das filosofias árabes", ligado à ÉPHÉ/CNRS, um colóquio intitulado "Descartes e a Idade Média". No ano seguinte, foi publicada pela Vrin, sob o mesmo título do colóquio (BIARD; RASHED, I997), uma coletânea de 24 artigos, dos quais nada menos que seis foram claramente dedicados à apresentação de "relaçôes" entre as filosofias de Guilherme de Ockham e Descartes. Podem ser somados a eles ainda outros dois, que mencionam tal "relação" de forma secundária. Para efeito de comparação, basta dizer que, entre os autores medievais, apenas Francisco Suarez e Tomás de Aquino são mais citados do que Ockham, nesse volume. A razáo disso parece estar num ponto preciso, que, ainda que com fins diversos, é frequentemente retomado nas propostas de análise da relação entre a Idade Média e a Modernidade:

Já está mais do que assente, por exemplo, que as primeiras origens da nova
problemática cultural que se afirmava vigorosamente no século XVII devessem ser
procuradas no empirismo da escola de Ockham, na identificaçáo ockhamista do
conhecimento com a cognitio sperimentalis $($ sic), no nominalismo: em todas aquelas
doutrinas que contribuíram para colocar em crise, desde o interior, o grande

${ }^{1}$ Professor do Departamento de Filosofia e Metodologia das Ciências da Universidade Federal de São Carlos. 
"compromisso" tomista e aquela traduçáo do cristianismo em termos aristotélicos sobre a qual estava baseada a cultura escolástica. (ROSSI, 2006, p. 68).

Mas, como se sabe, o problema é justamente definir qual o exato significado que se quer tomar pelo que aqui vagamente chamamos de "relação" entre a Idade Média e a Modernidade e que, no texto de Rossi, é classificado como a origem da problemática cultural do século XVII. Se, de um lado, há quem defenda haver na Modernidade náo muito mais do que a continuidade de um estilo de reflexão paulatinamente elaborado no período medieval (DUHEM, CROMBIE apud KOYRÉ, I982a), há também quem defenda que a passagem da Idade Média para a Idade Moderna não seja nada menos que uma Revolução (KOYRÉ, 1982b), ${ }^{2}$ ainda que, como de praxe, nem sempre haja acordo a respeito de todos os seus matizes, entre seus defensores. ${ }^{3}$ De outro lado, no que diz respeito mais diretamente à "relação" do pensamento de Ockham com o Moderno, ainda que insistentemente sejam vistos pontos de convergência entre ambos, não há clareza quanto ao modo exato em que podem ser traçadas suas pontes. Mais especificamente no caso das relaçóes entre Ockham e Descartes, há quem proponha uma comparação meramente "epistemológica" entre os dois pensadores, em temas que, dada a proximidade do assunto debatido, pode ser proveitoso traçar um panorama que leve a um esclarecimento do que é realizado por ambos ao se notar em que consiste a diferença de suas soluçóes:

Por isso vamos utilizá-la [sc. a distinção, ainda que anacrônica, entre naturalismo e normativismo como ponto de partida para uma interrogaçáo sobre a natureza e as conseqüências da teoria cartesiana da intuição] como um fio condutor na comparação dos dois filósofos [sc. Ockham e Descartes] esboçada aqui. Dissemos bem: esboçada, porque náo conhecemos os liames históricos, reais ou possíveis entre esses dois filósofos, e nosso escopo aqui não é o de estabelecê-los. Se escolhemos Ockham como ponto de comparação, foi

\footnotetext{
2 A esse respeito, leia-se Rossi (1992, p. 34): "A chamada Revolução Científica - que muitos 'medievalistas' procuraram apagar da história do Ocidente - teve realmente o caráter 'revolucionário' que foi tantas vezes sublinhado, porque não consistiu na modificação de resultados parciais no âmbito de um sistema aceito, mas no questionamento de todo esse sistema, na adoçâo de princípios contrários à 'razão' e à 'experiência', tal como vinham se configurando dentro da tradição, na construção de um novo quadro do mundo no qual se tornar problemáticas ou privadas de sentido muitas 'verdades' que tinham sido óbvias por quase dois milênios, enfim, na elaboração de um novo conceito de 'razão', de 'experiência', de 'natureza', de 'lei natural'. [...]".

${ }^{3}$ Para uma crítica de Rossi a certos aspectos da compreensão de Koyré da Revolução da ciência moderna, veja-se Rossi (I976, p. 116 s.) e o "Prefácio à terceira edição", escrito em 2003, de Rossi (2006, p. 7-46, especialmente p. 36-40). Uma crítica à própria compreensão de Revolução científica e, especialmente, ao modo como ela é proposta por Koyré na qual, porém, as conclusốes por vezes parecem mais duras do que permitem suas premissas, pode ser vista em Panza ( 200I).
} 
porque, como Descartes, ele concilia um lugar central à intuição como fonte de conhecimento. (ALANEN; YRJÖNSUURI, 1997, p. 156).

Há, por outro lado, quem defenda que, de fato, ao menos quanto a certos aspectos de sua discussão, "Descartes se insere em certa tradição medieval que encontra sua origem em Ockham" (PERLER, 1997, P. 142; BIARD, 1997; RENAULT, 1997; ROBINET, 1997; ROSSI, 1992), ainda que nem sempre fiquem muito claros os meios pelos quais é possível traçar a constituição dessa "tradiçâo". Sabe-se que um ponto intermediário desse debate é frequentemente encontrado na figura de Francisco Suarez (COURTINE, I990, p. 170-175), e também conhecemos ao menos uma tentativa de se traçar uma linha de continuidade mais detalhada entre o que será chamado de um modo muito geral de "movimento ockhamista" e a revolução científica da Modernidade (BOTTIN, 1982). Ante a dimensão da discussão, nossa proposta aqui correrá o risco de parecer decepcionante, uma vez que ela não irá além de propor uma breve recensão que mostre, em primeiro lugar, como o pensamento de Ockham aparece - ainda que analisando não mais que uma parte diminuta da historiografia recente - geralmente ligado com o mecanicismo e com a ciência Moderna e, depois, tentar identificar alguns dos contornos e dos limites dessa relação.

\section{SOBRE A "MODERNIDADE" DE OCKHAM}

É a um livro de C. Prantl sobre a história da lógica no ocidente (Geschichte der Logik in Abendlande), publicado em Leipzig, em 1927, que geralmente se atribui a responsabilidade de ter resgatado a Ockham de um longo esquecimento: "[...] depois de ter imperado nas Escolas dos séculos XIV e XV", Guilherme de Ockham não seria mais do que um nome que teve a sorte de "[...] transpor os umbrais dos livros de textos escolásticos" perfilado à lista dos "Adversarii" do que era então apresentado como sendo "o" pensamento escolástico (ANDRÉS, I969, p. 9 s.), ou seja, o pensamento de Tomás de Aquino e o "tomismo". Desde entáo, a descrição do pensamento ockhamiano pela historiografia do início do século XX teria reproduzido opinióes que iam desde as que o reputavam náo mais do que "[...] a principal causa do colapso do Escolasticismo" (cf. BOEHNER, I958a, p. 26) até o extremo oposto, considerando-o nada menos que "[...] o criador das bases da ciência moderna” (ANDRÉS, I969, p. 17).

Ainda que esses extremos possam até mesmo ser vistos como nada mais do que os lados de uma mesma moeda, parece interessante lembrar que o principal propagador de um deles foi Étienne Gilson, para quem “o 'ceticismo' e o 'criticismo' ockhamista e pós-ockhamista” teriam sido os principais baluartes de 
uma “'crise do século XIV', apreendida por Gilson como a 'desintegração de uma

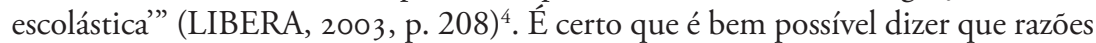
não faltaram para tais apresentaçóes. As polêmicas suscitadas desde o entorno da primeira metade do século passado até os dias de hoje passaram por percalços diversos: inicialmente, a falta de comentários que abordassem o autor diretamente de suas fontes; depois, a dificuldade de se disponibilizarem textos de Ockham que fossem suficientemente seguros para a pesquisa (BOEHNER, I958b; ANDRÉS, I 969, p. 9-20); por fim, a falta de consenso em se encontrar uma abordagem que eleja um ponto de partida que permita descrever coerentemente os vários aspectos da obra ockhamiana.

Mas, mesmo que persistam divergências quanto à interpretação de certos aspectos do pensamento ockhamiano, também já é possível identificar certa maturidade em seus estudos, visto que, desde fins da década de 1960, já se pode dizer que são vários os trabalhos que o abordam “[...] não em funçáo de outros pensamentos, mas em função de si mesmo, isto é, na compreensão equilibrada do que o todo da obra de Ockham representa de contribuição ao pensamento universal da Filosofia e em concreto da Filosofia Medieval" (ANDRÉS, I969, p. 18 s.). A resenha de um desses trabalhos que apresentam uma boa visão de conjunto do pensamento de Ockham assim descreve o que pode ser visto como um resumo de seus pontos principais e da "agenda" que o pensamento de Ockham propôs, à sua época:

Com Ockham, a ontologia é deixada em suspenso, se não destruída. A metafísica não é mais uma ciência, nem tampouco um domínio de discurso

\footnotetext{
${ }^{4}$ O livro de Libera tem como ponto de partida uma crítica da caracterização do que Gilson chama de a "crise do século XIV", que não teria feito mais do que dissolver a obra tomasiana de "unir numa síntese sólida a teologia natural e a teologia revelada", em que o conhecimento natural e os dados da fé apareceriam como "elementos de um único sistema intelectual" (p. 7 s.). Mostrando a insuficiência dessa caracterização, tanto quanto ao papel de Tomás e dos autores do século XIV a partir de uma apresentação da filosofia de Alberto Magno, mestre de Aquino, Libera aponta os limites e as incorreçóes de várias das leituras que nela estáo baseadas, como é o caso de Durkheim em sua apresentação sobre o "drama da escolástica" e, segundo o tema principal do livro, da epístola papal de 1998, intitulada: Fides et ratio (2. ed. São Paulo: Paulinas, 1998).

5 O teor das polêmicas que envolveram a interpretação dos escritos de Ockham, por volta da primeira metade do século passado, pode facilmente ser verificado nos vários artigos publicados por Boehner. Como exemplo, veja-se Boehner (1958c), uma dura crítica ao capítulo que De Wulf escreveu sobre Guilherme de Ockham, no terceiro tomo de sua Histoire de la Philosophie Médiévale, publicada em 1947. Um exemplo atual das divergências na leitura de Ockham pode ser visto nos artigos de STUMP, E., The Mechanisms of Cognition: Ockham on Mediating Species, e de KARGER, E., Ockham's Misunderstood Theory of Intuitive and Abstractive Cognition, em Spade (I999, p. 168226). Para Spade, as autoras apresentam visóes opostas que nos fornecem "[...] um perfeito exemplo do vivo debate sobre o ensino de Ockham.” (ibidem, p. 13). Para uma resenha atual das várias linhas interpretativas do pensamento ockhamiano, veja-se König-Pralong (2005, p. 186 ss).
} 
convenientemente constituído. A teologia, enfim, nấo pode ser senão negativa, na falta de alguma experiência possível de Deus. Sem dúvida, não se deveria mesclar muito rapidamente o venerabilis inceptor nos debates dos tempos modernos, ou nos de nosso século. Combinemos, no entanto, ao lê-lo, que a filosofia tem tudo a ganhar numa redescoberta da modernidade dos medievais. (DROIT, I989).

Droit argumenta que, numa filosofia que propóe como única realidade a existência dos singulares, em que os universais não são mais do que signos mentais regidos pelas regras da lógica, não resta senão perguntar

[...] o que, em nossa experiência, permite constituir as séries (as pedras, as árvores, os homens), concedendo sua unidade mental a essas semelhanças de unidades dispersas. Cada série sendo designada por um signo (os termos 'pedra', 'árvore', 'homem'), tratar-se-á de quais combinaçôes desses signos podem se referir adequadamente a esta ou aquela realidade singular.

E, o mais importante para nós aqui, numa clara advertência ao leitor (e no que pode ser visto como uma provocação ao autor do livro que era então por ele resenhado), previne-nos de mal avaliarmos a novidade da obra apresentada: é preciso cuidar para não enxergar na filosofia de Ockham aquilo que, a princípio, pode não estar lá, a saber, os debates próprios aos "tempos modernos", ocultando, assim, ainda que inadvertidamente, a "modernidade dos medievais", ou seja, aquilo que, de fato, o pensamento medieval tem de próprio e, acrescentemos, que pode nos levar a melhor entender em que de fato consiste a "modernidade" dos Modernos.

Em seu livro Guilherme de Ockham: o singular (1989), Piérre Alféri defende abertamente a tese de que a redução ockhamiana da existência aos singulares implica consequências que podem levar à física moderna. Dado que só há singulares, apenas há sentido em se falar da matéria como uma parte do singular, se ela for uma coisa atualmente existente, à qual só pode ser atribuída como característica distintiva a propriedade da extensáo, propriedade lógica da matéria, inseparável de seu conceito: "É somente a partir desse liame lógico que ela se determina como uma propriedade física, a saber, a quantidade". Ora, destaca Alféri, essa consequência tirada de um ponto fundamental da filosofia ockhamiana tem como único resultado possível uma completa reformulação da física aristotélica:

O ente singular encerra, assim, de modo decisivo a indeterminação da matéria aristotélica. Pensando-a de modo essencialmente quantitativo, a ontologia do singular funda de modo programático um conhecimento da matéria enquanto tal. Além disso, uma vez que ele é sempre finito e circunscrito no singular, seu conhecimento não pode ser senão ele mesmo singularizado, isto é, experimental. Assim, é pensada, pela primeira vez, a possibilidade ontológica de uma física náo aristotélica, experimental e quantitativa. De fato, um fio contínuo partindo das 
primeiras formulaçôes do primado da singularidade no final do século XIII passa por Ockham e conduz à física moderna, à redução das qualidades aristotélicas a quantidades intensivas, à descoberta do princípio de inércia e do movimento da terra, à idéia de um universo infinito. (ALFÉRI, 1989, p. 97).

Em que consiste esse fio? Quais são as principais características da filosofia ockhamiana que podem contribuir para a constituição da física moderna? Eis ao menos duas questóes que, parece, deveríamos nos propor. Comecemos pela resposta da segunda e, nela, pela noção de experiência.

Vimos já por duas vezes aqui expressa a ideia de que a noção de experiência proposta por Ockham serviria como a base de "uma ciência não aristotélica" (Alféri) ou, até mesmo, da origem da nova problemática cultural do século XVII (Rossi). Mas, afinal, o que Ockham entende por "experiência"?

Três curtas passagens da Ordinatio ockhamiana parecem suficientes para contextualizar sua opinião. A primeira delas aparece logo na primeira questão do prólogo da Ordinatio, numa discussão cujo tema é o conhecimento. Nela, Ockham descreve que, quando alguém conhece alguma verdade contingente de modo que ela não possa ser igualmente conhecida por alguém que não teve a experiência daquilo que é conhecido, tal como, digamos, é diferente o modo pelo qual conhecem Sócrates aquele que esteve com Sócrates e aquele que dele apenas ouviu falar, então, aquele que esteve com Sócrates tem dele uma "notícia experimental", uma notitia ou cognitio experimentalis (cf. Оскнам, OTh I, p. 32, lin. 21-p. 33, lin. 2), tal como se lê acima, na citaçáo do texto de Rossi. Sendo assim, a notícia experimental de Ockham não é senão o conhecimento que, dada a própria coisa conhecida, é tido a partir de algum dos cinco sentidos ou da conjunçáo de alguns ou de todos eles, nada mais. Ou melhor, é o conhecimento de uma coisa, quando ela mesma é recebida por um ou mais dos sentidos daquele que a conhece. Até aqui, nada que escape, em linhas gerais, às ideias do texto aristotélico. Basta lembrar, por exemplo, as discussóes no De anima sobre os sentidos e o "sentido comum".

A segunda passagem na qual Ockham alude à experiência, na segunda questão desse mesmo prólogo, relaciona-a com a ciência, traçando uma comparação entre a conclusão que é demonstrável através de princípios conhecidos por si [sc. "principia per se nota”] e a que é demonstrável através de princípios conhecidos unicamente por meio da experiência [sc. "principia nota tantum per experientiam"] (cf. OCKHAM, OTh I, p. 83, lin. 22-25). Mais uma vez, a diferença baseia-se em situação paralela à já comentada: aquilo que é demonstrável pelos "princípios conhecidos unicamente por meio da experiência” é o que é conhecido por meio da notícia experimental já descrita. 
Por fim, há uma passagem que poderá nos ser útil. Na questão doze do prólogo, Ockham afirma que "[...] muitos são os universais que não podem ser conhecidos [sc. sciri] senão através da experiência dos sentidos e do intelecto", pois, "[...] pela experiência, adquire-se o universal que é o princípio da arte e da ciência” (cf. OCKHAM, OTh I, p. 350, lin. 11-19). Mas aqui náo parece senão que voltamos mais uma vez àquilo que já havia sido anunciado por Alféri: o conhecimento do universal baseia-se, por várias vezes, no conhecimento do singular, que, como vimos, em certo sentido, deve ser tomado por "experimental". Veremos já algumas das consequências da assunção dessa tese, mas, antes, talvez não seja inapropriado seguir o conselho de Droit e lembrarmos um caso em que a falsificação da compreensão de experiência para os medievais levou a uma série de más interpretaçôes: Rogério Bacon, confrade de Ockham. Sobre essa confusão, escreveu Hedwig (2005, p. 203):

Os critérios da ciência experimental moderna não são formulados por Roger Bacon, mas apenas mais tarde por Francis Bacon, que distingue experientia e experimentum com rigor metódico: uma experientia tomada de maneira aleatória ou "a esmo" é casual; mas se ela é "procurada" segundo uma ordenação experimental planejada de antemão e de maneira explícita, entáo ela se transforma em "experimento": "si quaesita sit, experimentum est" (Nov. Org. I, 82). A ciência - como postula F. Bacon - não trabalha, portanto, com um conjunto de relatos de experiência, mas com resultados que possam ser controlados metodicamente, fixados em tabelas, qualificados e ampliados em séries de experimentos "ab experimentis ad experimenta"). A partir desses dados ratificados podem ser extraídas leis da natureza ("axiomas"), que por sua vez podem ser testadas e complementadas por outros experimentos ("ex axiomatibus constitutis rursus experimenta nova"). A novidade dessa experiência planejada de maneira sistemática reside em que, nela, situaçôes complexas da vida real podem ser isoladas artificialmente e separadas como setores, de modo que se possa repeti-las aleatoriamente e medi-las de acordo com parâmetros fixos. Somente conhecimentos assegurados, como esses, e além deles nenhum outro pressuposto, servem de apoio às ciências modernas, que, para a conformação de teorias, trabalham com dados controlados e com os métodos da matemática (os métodos da quantificação). ${ }^{6}$

\footnotetext{
${ }^{6}$ Veja-se também Rossi (I992, p. 141-143, em especial): “[...] o ponto a sublinhar é outro: as observaçôes e as experiências que são importantes e decisivas para a ciência da natureza e para o controle da natureza desenvolvem-se e efetuam-se num plano que não é o da experiência quotidiana e das coisas visíveis ao olhar." Quanto à relação entre R. Bacon e a matemática, também vista como um "signo" da Modernidade nesse pensador, Nascimento (I995, p. 138 s.) enfatiza que, apesar de introduzir "[...] um elemento 'herético"” na física aristotélica, a saber, "[...] a idéia de tratar geometricamente os movimentos segundo a forma”, Bacon permanece nela, pois ainda “[...] se coloca no De multiplicatione dentro dos quadros da física aristotélica”.
} 
Visto isso, já é possível perceber que não é na identificação da cognitio experimentalis com o experimentum baconiano que se vislumbra a "modernidade" de Guilherme de Ockham. Mas, por isso mesmo, persiste a pergunta: afinal, o que teria vislumbrado Alféri (e Rossi), para dizer que a filosofia ockhamiana levaria de algum modo à física moderna? Ainda náo parece ser o momento de responder a isso. Antes, passemos à análise de mais dois elementos que podem contribuir na formulação da resposta dessa pergunta: a questão da causalidade e a relação da filosofia ockhamiana com a teoria do impetus e a lei de inércia.

Em seu livro sobre a física de Ockham, O. Larre retoma, onze anos depois, a mesma ideia já anunciada por Alféri: a primazia do singular, proposta por Ockham, teria na física duas consequências fundamentais. A primeira, considerar que o objeto próprio da física, ao contrário do que propunham as concepçóes aristotélica e tomista da física, seria o "objeto individual". A outra, "[...] que todo o sistema de causas necessárias e ordenadas que constituíam a estrutura do cosmos platônico e aristotélico cede seu lugar a um universo fragmentado em numerosos entes isolados, absolutamente contingentes, porque dependem da livre escolha divina" (LARRE, 2000 , p. 127). Os pressupostos de tal reformulaçáo ainda são os mesmos: se tudo se reduz ao conhecimento do singular e se a essência das coisas não é mais do que a sua existência (OCKHAM, OTh IX, p. 141-145), não há sentido em se falar de causas que, de algum modo, condicionem o modo de ser das coisas. Para Ockham, há apenas duas causas: a eficiente e a final, "[...] visto que as causas material e formal são concebidas como princípios de existência individual”. Mas, em certo sentido, mesmo a causa final acabará sendo excluída: "[...] a causa final acaba subsumida sob a compreensão da causa eficiente: $\mathrm{o}$ fim se reduz à atividade intencional de um agente" (LARRE, 2000, p. 128; 138; ALFÉRI, 1989, p. 94).

Para Koyré (1982a, p. 71 s.), é inegável que a crítica ockhamiana à teoria das causas aristotélicas "[...] tenha desempenhado um papel importante ao desentulhar o terreno sobre o qual podia edificar-se a ciência moderna e ao suprimir certos obstáculos que se antepunham a essa edificação." No entanto, Koyré não hesita: "Mas, duvido muito que ela tenha sido alguma vez um fator positivo no desenvolvimento científico."

Podemos ainda visualizar nesse mesmo texto de Koyré que tipo de opinião Alféri tem sob os olhos, ao afirmar que há "um fio contínuo" que, de Ockham, "[...] conduz à física moderna, à redução das qualidades aristotélicas a quantidades intensivas, à descoberta do princípio de inércia e do movimento da terra, à idéia de um universo infinito". Analisando os livros de A. C. Crombie ${ }^{7}$, Koyré mostra

CROMBIE, A. C., Robert Grosseteste and the Origins of Experimental Science, 1100-1700. Oxford: Clarendon, 1953; idem, Augustine to Galileo. Londres: Falcon, 1952. 
que o historiador defende a tese de que, ao criticar a teoria aristotélica das causas, Ockham "[...] reduzia o conhecimento à simples observação das seqüências de fatos e acontecimentos." "Nada mais que um experimentador", Ockham "[...] incitava os filósofos da natureza a esforçarem-se por conhecê-la através da experimentação" (ibidem, p. 66). No entanto, segundo Crombie, Ockham nada teria a ver com os trabalhos matemáticos e cinemáticos de Nicolau de Oresme, a elaboração da teoria do impetus por este e Buridano, a possibilidade de um movimento diurno da Terra. Ockham, pelo contrário, teria rejeitado a teoria do impetus "em favor de uma concepção que ele [sc. Crombie] assimila - com muitos outros historiadores - à concepção da inércia no século XVII." (ibidem, p. 72). ${ }^{8}$

Contrário a esse juízo, Koyré julga ser impossível deduzir do texto de Ockham "[...] concepçóes como, por exemplo, as da conservação da direção da velocidade que implica a concepçáo moderna do movimento", e, portanto, atribuir-lhe "a descoberta do princípio de inércia." Segundo Koyré (1982b, p. 162), a crítica de Ockham à física aristotélica se uniria a uma tradição que vem desde pelo menos Hiparco (séc. II) e Filáo (séc. I a.C. - I d.C.). Depois, Bottin (1982, p. 240) acrescentaria ainda à lista Filopono (séc. VI) e os filósofos árabes. A quo moveantur projecta? Pelo que é movido aquilo que é lançado? Eis a questão, propóe-se, que parece pôr em xeque a teoria aristotélica. Koyré (1982b) explica que, para Aristóteles, há basicamente dois tipos de movimento: o movimento natural e o movimento violento. No movimento natural, a causa ou o motor do movimento é a própria natureza daquilo que é movido, sua "forma", que busca reconduzi-lo a seu lugar "natural”. Para Aristóteles, tudo tenderia ao repouso:

8 Sabemos, no entanto, que a fonte de Alféri é P. Duhem, apontado por Koyré nessa passagem (cf. 1982a, p. 79, nota 13) e por todo o artigo, como um defensor de teses semelhantes às de Crombie. A crítica de Koyré a Duhem pode ser vista também em Koyré (1982b e 1982d).

9 Ao final, Koyré emite ainda um duro parecer a respeito da filosofia de Guilherme de Ockham: "Não nego que, como disse Anneliese Maier, a concepção de Occam teria podido desenvolver-se e chegar ao movimento concebido como estado. Para mim, é suficiente verificar que náo foi esse o caso. E que nenhum dos numerosos discípulos do Venerabilis Inceptor jamais tentou fazê-lo. O que é, pelo menos, para mim, a prova de sua perfeita esterilidade. De fato, o método nominalista conduz ao ceticismo e não à renovação da ciência" (ibidem, p. 72). Note-se, a esse respeito, que uma das fontes para o juízo de Koyré é seguramente Gilson, de quem Koyré é próximo inclusive quanto à sua formação intelectual, como o destaca Libera (1999, p. 37). Poderíamos avançar ainda que o ceticismo ockhamiano, do qual muito se fala, não parece senão uma versão da crítica que a escola escotista (cf. LIBERA, 1996, p. 332 335) apresentou à identificação ockhamiana da unidade numérica à unidade real: "Se toda diferença real é uma diferença numérica, a diferença entre os gêneros e as espécies não será mais do que uma simples distinção de razão" (p. 335), isto é, se "animal" e "homem" não são mais do que distinçôes de razão, o que faz com que, de fato, Sócrates e Platão sejam "homens”? Que sentido haverá em dizer que Sócrates e Platão são indivíduos de uma mesma espécie? Uma tentativa de resposta a essas questôes pode ser encontrada em Goddu (1984, p. 216-219). 


\begin{abstract}
A concepçáo de "lugar natural" é baseada numa concepção puramente estática da ordem. Com efeito, se cada coisa estivesse "em ordem", cada coisa estaria em seu lugar natural e, bem entendido, ali ficaria e permaneceria para sempre. Por que sair dali? Pelo contrário, ofereceria uma resistência a todo esforço no sentido de afastá-la. Não se poderia expulsá-la dali senão mediante algum tipo de violência e, se em conseqüência de tal violência, o corpo se pusesse fora de "seu” lugar, procuraria voltar a ele. (KOYRÉ, 1982b, p. 158).
\end{abstract}

Segundo Koyré, Aristóteles defende que, no movimento, cada mudança precisa de uma causa para se explicar, isto é, precisa de um motor para produzir o movimento: "[...] o movimento não se mantém como ocorre com o repouso. O repouso - estado de privaçáo - não precisa da ação de uma causa qualquer para explicar sua persistência. $\mathrm{O}$ movimento [...] náo pode prescindir de tal ação. Retirada a causa, cessa o movimento. Cessante causa cessat effectus" (p. 159 s.). Assim, para Aristóteles, todo movimento que é contra a natureza, isto é, contra o lugar natural de um objeto e a seu repouso, "[...] exige, durante toda a sua duração, a ação contínua de um motor externo ligado ao corpo movido. Retirado o motor, o movimento cessa. [...] Para fazer com que um corpo se mexa, é preciso empurrá-lo ou puxá-lo. Náo existem outros meios" (p. 160). Disso surgem os problemas propostos à teoria aristotélica. Como o explica Bottin (1982, p. 239 s.):

[...] no lançamento dos projéteis é necessário hipotetizar a presença de um motor diverso daquele que produziu inicialmente o movimento (por exemplo, a mão que se separa da pedra depois de tê-la arremessado). Para esclarecer essa dificuldade, Aristóteles chega a supor que "os projéteis continuam a se mover, mesmo depois de cessado o contato com a mão que os lançou, por causa de uma mútua substituição, como dizem alguns, ou pelo impulso do ar, que impulsiona com um movimento mais veloz do que o movimento pelo qual o objeto é transportado naturalmente ao lugar próprio" (Física, 215 a 14-17).

Segundo essa leitura, após ser lançada (movida) por um arco, para continuar em movimento, a flecha teria de ser movida pelo ar até encontrar seu alvo. Caso não o encontrasse antes que o movimento do ar fosse vencido pelo movimento natural da flecha, seu movimento natural a transportaria ao seu lugar próprio, isto é, para baixo. Uma das críticas a essa explicação do movimento é representada pela teoria do impetus, que, grosso modo, defenderia que o motor transmitiria ao movido algo que o tornaria capaz de se mover, "[...] como alguma espécie de potência ou de força que passa do motor ao móvel e produz, então, o movimento" (KOYRÉ, 1982b, p. 162). Não é o caso de nos aprofundarmos aqui numa descrição acurada dessas teorias. Basta a nosso propósito saber que Ockham nega ambas as explicaçôes: "[...] ele nega que o movimento contínuo de um projétil seja devido ao ar circundante ou à qualidade do impetus." (GODDU, 1999, p. 
165). Para Koyré (1982b, p. 161 s.), o grande problema da teoria aristotélica e que a fez, como já apontamos, ter sido continuamente posta em xeque é o fato de que ela, "[...] a despeito - ou talvez por causa - de sua perfeiçáo teórica, apresentava um grave inconveniente: o de não ser, absolutamente, plausível, o de ser completamente incrível e inaceitável para o simples bom senso, o de estar, evidentemente, em contradição com a experiência mais comum.” Tenha ele razão ou não, o certo é que este não é o mote da crítica de Ockham.

Para Ockham, a palavra "movimento" é um termo conotativo, isto é, que significa uma mudança e, secundariamente, a própria coisa que sofre a mudança:

O movimento, diz Ockham, não é uma coisa realmente distinta, distinta do corpo que sofre o movimento e dos lugares sucessivos que o corpo ocupa. A mudança que um corpo sofre náo é distinta do corpo no ato de mudança. Tal mudança se refere à aquisição potencial de uma qualificação ou de uma parte de que o corpo agora carece ou no processo de aquisição. Referir-se à mudança e ao movimento como entidades distintas é cometer o erro de tomar um termo conotativo por um termo absoluto. "Movimento" é um termo conotativo, e o mau uso desse termo ilustra os perigos de usar termos abstratos como um tipo de atalho para expressóes e eventos mais complexos. (GODDU, I999, p. 156).

Em suma: o movimento, para Ockham, não é algo realmente distinto daquilo que é movido - como é o caso do ar na teoria aristotélica, ou de uma qualidade como o impetus na teoria de mesmo nome - mas se diz simplesmente que há movimento local, quando um corpo está num lugar e depois noutro, sem repouso intermediário. Goddu (1999, p. 156) e Larre (2000, p. 219) afirmam que é nessa identificação entre o movimento e o movido que muitos veem em Ockham aquele que deu o primeiro passo para a formulação do princípio de inércia ${ }^{10}$ :

Alguns comentadores de Ockham viram em sua negaçáo da existência do movimento uma negação de que o próprio movimento pode mudar, entâo que todo movimento tem de ser uniforme e que ali náo pode haver aceleraçáo. Mas o ponto de Ockham é outro. Ele reconheceu que os corpos sofrem tipos diferentes de movimento e que cada um requer uma descrição adequada ao tipo de movimento que o corpo sofre. Corpos que sofrem uma aceleração uniforme, por exemplo, não requerem que suponhamos que o movimento existe

\footnotetext{
10 Cf. KOYRÉ (1982c, p. 183): “O princípio de inércia é muito simples. Afirma que um corpo abandonado a si mesmo permanece em seu estado de repouso ou de movimento tanto tempo quanto esse estado não for submetido à ação de uma força exterior qualquer. Em outros termos, um corpo permanecerá eternamente em repouso, a menos que não seja posto em movimento. E um corpo em movimento continuará a mover-se e se manterá em seu movimento retilíneo e uniforme tanto tempo quanto nenhuma força exterior o impedir de fazê-lo [Cf. Isaac Newton, Philosophiae Naturis Principia Mathematica; Axiomata sive leges motus: Lex I: Corpus omne perseverare in statu suo quiescendi vel movendi uniformiter in directum, nisi quatenus a viris impressis cogitur statum illum mutare.].”
} 
independentemente do corpo em movimento e que o próprio movimento está aumentando de modo uniforme, mas unicamente que o corpo está se movendo com aceleração uniforme. (GODDU, 1999, p. 156).

Ora, se a definição ockhamiana de experiência nada tem a ver com o experimentum dos modernos, se a crítica da teoria da causalidade aristotélica também não parece ter contribuído em nada para a formulação de algum princípio da teoria da física moderna, em que, afinal, Ockham poderia ter contribuído para a "revolução científica" ou, em sentido mais geral, para a Filosofia Moderna, como afirmam náo só alguns de seus comentadores, como é o caso aqui citado de Alféri, Perler, Biard e outros, mas até mesmo alguns dos defensores daquela revoluçáo, como Rossi? Em que circunstâncias, ao menos no que diz respeito ao caso de Ockham, haveria algum sentido em se falar de "raízes medievais" para o pensamento moderno?

Do que vimos até agora, parece que de comum a todas as reflexóes que insistem em negar uma simples continuidade entre Idade Média e Modernidade está o negar que a contribuição da Idade Média resida em alguma maturação na formulação dos conceitos empregados pelos modernos. Em sentido contrário, o trabalho de seus defensores não parece se dedicar senão a refinar os argumentos que ajudariam a sustentar em que consistiria essa continuidade. É o caso do trabalho já mencionado de Bottin, que indicamos tentar traçar uma espécie de - retomando a Alféri - "fio contínuo" entre Ockham e os modernos, por meio da proposta de uma discussão "ockhamista". Bottin, concorde com seus críticos, não hesita em afirmar na conclusão de seu trabalho que "[...] nas obras de Galileu, reencontramos grande parte da terminologia medieval, mas tomada num contexto completamente diferente, isto é, aquele das 'experiências acuradas' ['sensate esperienze'].” No entanto, também não se furta a acrescentar a seguinte conclusão: "O que não impede que, em questôes teóricas relevantes, a contribuição dos físicos medievais não se reduza a fornecer uma terminologia esvaziada de seu significado originário, mas determine, ao menos quanto a explicações conceituais, as escolhas e as descobertas do cientista pisano" (1982, p. 354 s., grifos nossos).

Todavia, da conclusão de Bottin é possível perceber que a dificuldade continua a mesma: ainda que, no avançar das pesquisas ${ }^{11}$, sejamos obrigados a reconhecer

\footnotetext{
11 Inútil relembrar aqui as contribuiçốes iniciais de Gilson a esse propósito, em seus Index scolasticocartésien. 3. ed. rev. e aum. Paris: Vrin, 1979, e Études sur le rôle de la pensée médiévale dans la formation du système cartésien. 3. ed., ver. e aum. Paris: Vrin, 1967. (original de 1930). Aliás, o último capítulo deste livro, ao qual, nos parece, ainda não se deu suficiente atenção, não só alude à existência de uma escolástica do século XVII como mostra o diálogo e a crítica que ela manteve com o pensamento cartesiano. Parece impossível que algum trabalho que queira traçar as "relaçôes" entre a Idade Média e a Modernidade possa prescindir da análise desses textos, análise que, à época, Gilson considerava
} 
que a Modernidade tem a sua dívida para com a filosofia genericamente chamada pelos Modernos de "escolástica", resta medir em que sentido a discussão medieval é capaz de esclarecer a moderna. Quanto a isso, ainda que um duro crítico da filosofia ockhamiana e da tese da continuidade entre Idade Média e Modernidade, o próprio Alexandre Koyré parece já nos ter indicado a resposta: o pensamento de Ockham ganha importância para a compreensáo dos Modernos, na medida em que, de algum modo, sua crítica acabou por "[...] desentulhar o terreno sobre o qual podia edificarse a ciência moderna" e por "suprimir certos obstáculos que se antepunham a essa edificação." Arrancando-nos um pouco mais claramente dessa área de indefiniçấo, no mesmo sentido, Goddu acrescenta: "Se o mais importante primeiro passo rumo a um princípio inercial for o abandono dos princípios aristotélicos [sc. quanto a certas questóes da física], então restam poucas dúvidas de que a crítica de Ockham foi a mais devastadora e significante da idade média” (1984, p. 228).

\title{
2. OCKHAM E A "MODERNIDADE" DOS Modernos
}

Não é o caso, porém, de confundir Modernidade com antiaristotelismo. Mesmo que a crítica à filosofia de Aristóteles tenha sido um tema presente na obra de alguns autores modernos (como é o caso de Francis Bacon), mais do que o próprio Aristóteles, seu alvo é a revisão de certo "modo de filosofar". Segundo Rossi, para os Modernos, "[...] o erro dos aristotélicos é o de fixar e tornar eternos os problemas que Aristóteles suscitou”:

\begin{abstract}
Não pretendo deter-me sobre este tema, que é obsoleto, que foi, de certo modo, "esgotado" por tantos positivistas que identificaram Revolução Científica com antiaristotelismo. Não se trata disso. Essa recusa é uma defesa da variedade e do aspecto não-definitivo das filosofias, indica uma imagem diversa do saber e da ciência. Aquilo que a muitos parecia um mérito parece agora uma culpa: Aristóteles pronuncia-se sobre qualquer coisa e resolve as questōes "de modo a que tudo pareça claro e definitivo". Este justamente é o aspecto mais negativo de sua filosofia e é muito grave que, por obra de seus discípulos e sucessores, esse modo "esteja ainda em uso". [BACON, F., Scritti. Paolo Rossi (ed.). Turim: Utet, 1975, p. 579]. (ROSSI, 1999, p. 145 s.).
\end{abstract}

A citação de Rossi aqui não deve, porém, nos enganar. Na sua crítica de alguns aspectos da filosofia aristotélica, Ockham não está defendendo algo como o abandono dessa filosofia ou seu "aspecto não-definitivo". Ele vê "sua” filosofia como a filosofia de Aristóteles; sua exposição do livro da Física, como a exposição

impossível: "Une pareille histoire est actuellement absolument impossible. Nous ignorons presque tout de la marche qu'a suivie le cartésianisme dans les universités européennes au XVII ${ }^{\mathrm{e}}$ siècle [...]" (GILSON, I967, p. 317). 
da opiniāo do próprio Aristóteles. No prólogo de sua Exposição para os oitos livros da "Física" de Aristóteles, Ockham faz questão de destacar isso. Ali, ele diz não fazer mais do que expor a opiniāo do Estagirita, mesmo quando ela pareça contrária às "Sagradas Escrituras":

Visto que muitos tentaram expor os livros dele, pareceu-me conveniente, e a muitos que o pediram com insistência, gravar por escrito, para utilidade dos estudantes, meu modo de compreender a intençáo do Filósofo. [...] É assim, sem afirmaçóes temerárias, que quero explanar o que Aristóteles laboriosamente pesquisou. [...] $\mathrm{Na}$ verdade, se bem que o Filósofo, graças ao auxílio divino, tenha descoberto muitas e grandes coisas, misturou, levado pela fraqueza humana, alguns erros com a verdade. Portanto, ninguém me atribua as concepçóes que eu referir, pois que não procurarei expor o meu parecer de acordo com a verdade católica, mas o que esse filósofo aprovou ou acho que deveria aprovar segundo seus principios. (OCKHAM, OPh IV, p. 3 s., $\$ 1$, lin. 11-13.1517.24-29; OCKHAM, 1973, p. 341, grifos nossos).

E não parece que seja possível se dizer que Ockham faz tais afirmaçóes meramente por respeito à auctoritas, ou seja, para não ser visto como alguém que abandonou as opiniōes “do Filósofo”, Aristóteles. O próprio André Goddu defende esse ponto de vista: "[...] em suma, Ockham foi um aristotélico" (GODDU, 1999, p. 144 s., 155). O que implica dizer que a conclusão de Goddu, reproduzida pouco acima, segundo a qual a crítica ockhamiana resultaria no abandono dos princípios aristotélicos, náo é mais que uma tentativa de resposta às provocaçóes de uma pretensa "modernidade" ockhamiana, ainda que também essa resposta apareça anacrônica: Ockham só pode ser visto como “[...] abandonando os princípios aristotélicos" a partir do ponto de vista de um Moderno. Nada estaria mais longe de sua própria opinião. É claro que, como defende Bottin ao propor o termo "ockhamistas", isso não impede que a filosofia ockhamiana tenha de algum modo pautado as discussóes que historicamente dela foram contemporâneas, bem como as que destas tenham se seguido:

Por todos esses motivos [principalmente, o fato de que um caráter comum à cultura tardo-escolástica "não pode ser deixado de lado pelo fato de que ele não poderia ser encerrado em etiquetas historiográficas que terminariam por deixar na obscuridade o que deveríamos esclarecer"], fiz, de propósito, uso de um termo historiográfico genérico como "ockhamismo" no sentido de que a sua assunção é a mais lata possível; mantenho, de fato, que as doutrinas de Ockham, no que diz respeito à ciência, não possam ser consideradas uma verdadeira e própria escola de pensamento senáo numa mínima parte, mas sobretudo uma indicação de método ao afrontar os problemas mais diversos. (BOTTIN, 1982, p. 16). 
No entanto, sem prejuízo ao excelente livro de Bottin, essa ainda parece uma história que está por ser escrita. Para ficarmos num exemplo que diz respeito ao que aqui já mencionamos, não aparece claro, a partir dos elementos oferecidos por Bottin, o modo pelo qual é possível julgar que a exposição de João Buridan sobre a teoria do impetus possa ser reduzida a uma reação às opinióes ockhamianas ou mesmo como ela tenha sido de algum modo pautada pelo "método" ockhamiano. Certamente, há estudos que indicam a existência de certa relação entre esses pensadores, como, por exemplo, Perini-Santos, 2006, p. 182: "Buridan aparece, com efeito, sobre as pegadas ockhamianas, na adoção de uma descrição causal do conhecimento, mas corrigindo-a, através de uma abordagem mais fina da causalidade mental que lhe permite evitar um fechamento dedutivo muito forte do sistema de crenças. [...]" ${ }^{12}$ Ainda assim, tal como escreveram Alanen e Yrjönsuuri, dado o estado atual das investigaçôes, ainda não saberíamos dizer se é possível falar em caminhos que tracem o desenvolvimento de uma discussão desde Ockham até a Modernidade. O fato, digamo-lo mais uma vez, é que estamos diante de um campo de investigaçóes que está ainda por ser explorado. Basta lembrar - numa opinião que nos parece completamente infeliz, no que concerne à caracterização dos séculos XIV-XV ${ }^{13}$ que ainda há pouco, no início dos anos 2000, há quem escreva:

\begin{abstract}
Em síntese: torna-se difícil, certamente, estabelecer a influência dos pensadores medievais sobre os do século XVII pelo fato de que entre ambos náo se observa uma continuidade no desenvolvimento histórico: o período de originalidade escolástica chegou a seu termo em fins do século XIV, orientando-se logo o interesse rumo à literatura e às artes plásticas. (LARRE, 2000, p. 220 s., grifos nossos).
\end{abstract}

Finalmente, no que tange às relaçôes entre a "física aristotélica" e o mecanicismo do século XVII, passemos, antes de tudo, a uma caracterização que mostre o que há

\footnotetext{
${ }^{12}$ A esse respeito, veja-se também o "Préface à la deuxième édition" de Biard (2006, em especial, p. IV e V): "L'impact des mutations auxquelles Guillaume d'Ockham donne une impulsion décisive et dont Buridan représente la mise em oeuvre systématique dans le champ de la philosophie naturelle est donc incontestable. Mais n'est-ce pas surestimer tout de même ce qui revient au Venerabilis Inceptor? [...] Je répondrai à ce soupçon que, de fait, la position philosophique de Guillaume d'Ockham me parait avoir une portée critique forte, procédant d'une véritable «critique de la raison linguistique» et met em place les conditions d'une approche nouvelle des discours tenus par les sciences réeles» (sic) - philosophie naturelle et théologie. Cette approche ne s'imposera pas partout et de façon suivie, confrontée qu'elle doive être non seulement à diverses formes de réalisme logique, mais aussi à des conceptions physiques appuyées sur d'autres lectures interprétatives du corpus de philosophie naturelle, qu'elles soient "calculatrices" ou "averroïstes", deux tendances qui vont se côtoyer et se croiser tout au long des deux siècles qui suivent. On ne saurait assurément réduire toute la pensée d'un siècle ou d'une époque à une tendance ou à un courant. C'est une ligne de force, dominante peut-être à un certain moment, mais qui n'éclipse pas les autres. Néanmoins, j’ai essayé de le montrer avec le «contre-exemple» de Burley, la logique du signe imprègne l'ensemble des débats sémantiques de l'époque. [...]”

13 Veja-se, por exemplo, Libera $(1993,1996,1998)$.
} 
de próprio no mecanicismo em sua formulação moderna. Afinal, sabe-se que a ideia de um mundo concebido como um sistema de corpos em movimento e caracterizado como uma grande máquina pode ser encontrada, desde a antiguidade, por toda a história da filosofia. No entanto, o que caracteriza o mecanicismo moderno não é simplesmente a redução da natureza a um sistema de determinaçóes mecânicas, que considera os fatos naturais "[...] como movimentos ou combinaçóes de movimentos de corpos no espaço"14. De acordo com Rossi (1999, p. 134),

[...] naquilo que chamamos de mecanicismo do século XVII opera não só a idéia de que os eventos naturais podem ser descritos mediante os conceitos e os métodos daquele ramo da física chamado mecânica, mas opera também, e com força extraordinária, a idéia de que os engenhos e as máquinas construídas pelo homem podem constituir um modelo privilegiado para a compreensão da natureza.

Com isso, além de se mostrar diferente de qualquer outro tipo de "mecanicismo" que o tenha precedido, fica clara também mais uma vez a rejeição moderna a toda a concepção aristotélica de natureza, de lugar natural, da diferença entre a natureza e a arte. Ainda conforme Rossi, "[...] algumas das colocaçóes aristotélicas relativas à relação arte-natureza, acabaram aqui conscientemente arruinadas”:

Entre os objetos naturais e os artificiais não se dá nenhuma distinção de essência. $\mathrm{O}$ raio, que os antigos negavam que pudesse ser imitado, foi de fato imitado na época moderna. A arte não é o "macaco" da natureza e os produtos da arte não são algo inferior aos naturais. Sobre esse ponto, Descartes insiste de modo igualmente enérgico: "não há nenhuma diferença entre as máquinas que os artesãos constroem e os diversos corpos que unicamente a natureza compóe senão essa: que os efeitos das máquinas dependem unicamente da ação de tubos ou molas e de outros instrumentos que, devendo ter alguma proporçáo com as mãos daqueles que os construíram, são sempre tão grandes de modo que se fazem visíveis suas figuras e os seus movimentos, enquanto, por sua vez, os tubos ou as molas que produzem os efeitos naturais são geralmente muito pequenos para poderem ser percebidos pelos nossos sentidos..." [Descartes, Ouvres, Ed. Adam et Tannery, IX, p. 321 (Principia)]. O produto da arte, a máquina, serve de modelo para conceber e compreender a natureza. Não que a arte seja a própria natureza, mas a natureza é algo semelhante a um produto da arte. (ROSSI, 1962, p. 141 s.).

Outro aspecto a ser considerado na recusa dos Modernos do “[...] aspecto definitivo do aristotelismo", ou, o que dá no mesmo, na recusa ao escolasticismo, é que ela não implica a rejeiçâo do aspecto religioso: "[...] a glória de Deus e a utilidade pública", eis o lema que os "artesãos" e "engenheiros" do século XVI terão

\footnotetext{
14 Veja-se, por exemplo, a descrição de mecanicismo dada por Abbagnano (Diccionario de Filosofía.
} México: Fondo de Cultura Económica, 1992 (1961), verbete "mecanicismo"). 
como justificação de sua obra (ROSSI, I 962, p. 75). A crítica de Francis Bacon à escolástica aristotélica, antes que uma crítica à religiâo, é uma crítica a uma "[...] típica forma de impostura religiosa” (ROSSI, 1999, p. 67). Em suma, que fique bem claro: religiosidade e Modernidade não são necessariamente excludentes. Contudo, é necessário perceber, para nós que estamos interessados nas relaçóes Idade Média/Modernidade, a mudança de papéis aí sofrida. Obviamente, há opçóes teóricas que tornam religiâo e ciência coisas excludentes, na medida em que constituem campos de saber que tratam de assuntos, no mínimo, diferentes. Francis Bacon, por exemplo, defenderá que as opiniốes científicas modernas não podem ser encontradas nos livros sagrados: "O livro das Escrituras revela a vontade de Deus, e o da natureza a sua potência. [...]” (ROSSI, I999, p. 98).

Essa opinião, defende Rossi, se deve ao próprio modo como Bacon encara a natureza: uma selva, na qual não há espaço para "sistemas" fechados. Completamente diverso seria o ponto de vista de Galileu:

\begin{abstract}
Ao contrário do "empirista" Bacon, que concebe a natureza como uma selva, que vê no método um meio de ordenaçáo e de classificação da realidade natural, Galileu vê na natureza a manifestaçáo de uma ordem e de uma estrutura harmônica de tipo geométrico, vê um livro escrito em caracteres matemáticos, que só é legível quando se conhecem os caracteres particulares em que foi escrito. Esse livro, assim como o da Escritura, foi escrito por Deus. [...] Para Galileu, era necessário - e sobre isto eram fundadas suas vãs esperanças - que os teólogos, antes de pronunciar-se sobre o significado de muitas expressôes contidas no texto bíblico, ouvissem o que tinham a dizer aqueles que haviam efetuado essa difícil leitura. (ROSSI, 1999, p. 101).
\end{abstract}

De um lado, o alcance do método, de outro, a imagem de um universo que é a "[...] obra de um Deus que compóe o mundo numero, pondere et mensura" (ROSSI, 1999, p. 123). Mais do que uma concepção religiosa, estão em jogo duas concepçôes de natureza. Aliás, o uso da citação do livro da Sabedoria 11, 20, na Vulgata: "Sed omnia in mensura et numero et pondere disposuisti" - "Tudo dispusestes com medida, número e peso", utilizada na Idade Moderna para invocar a imagem de um Deus geômetra, nem sempre precisará ser visto como a expressão efetiva de qualquer tipo de religiosidade. Basta recordar, de um lado, que o tema de uma ordenação segundo um peso, número e medida pode ser encontrado num contexto completamente independente do da cultura judaicocristâ: a República de Platão (livro X, 602d-603a). De outro, que nem mesmo há a certeza de que, entre os modernos, o texto bíblico traga mais do que a ideia de certa ordem natural. ${ }^{15}$ Talvez o "deslize" de significados que Ginzburg (2003)

\footnotetext{
15 Veja-se, por exemplo, o artigo de Gabbey (200I).
} 
reclama a respeito das mudanças históricas na interpretação de um texto de Paulo, o apóstolo, entre o medievo e a modernidade se aplique também aqui. Talvez esse não seja senão mais um exemplo do uso de uma terminologia alheia, "[...] tomada num contexto completamente diferente".

OLIVEIRA, Carlos Eduardo de. On some interpretations about the relationships between Ockham's Philosophy and the Physics of the Modern Age. Trans/Form/Ação, Marília, v. 34, n.3, p. 69-88, 2011.

ABSTRACT: In this paper we analyze some of the many interpretations defending a relation between modern philosophy, empiricism and ockhamian physics. Trying to clarify some assumptions of these interpretations, we intend to point out some of its limits, trying to achieve a more accurate description of the problem faced by them.

KEYWORDS: William of Ockham. Physics. Aristotelianism. empiricism. Middle Ages. Modern Ages.

\section{REFERÊNCIAS}

OCKHAM, G. Opera Philosophica (OPh), vol. I-VII et Theologica (OTh), vol. I-X. Nova Iorque: Universitatis S. Bonaventurae, 1967-1988.

. Seleção de Obras. Traduçáo e notas de Carlos Lopes de Mattos. Os Pensadores, vol. VIII. São Paulo: Abril Cultural, 1973, p. 341-404.

ALANEN, L.; YRJÖNSUURI, M. Intuition, jugement et évidence chez Ockham et Descartes.. In: BIARD, J. ; RASHED, R. (Ed.). Descartes et le Moyen Age. Paris: Vrin, 1997, p. 155-174.

ALFÉRI, P. Guillaume d'Ockham. Le Singulier. Paris: Minuit, 1989.

ANDRÉS, T. El nominalismo de Guillermo de Ockham como Filosofía del Lenguaje. Madrid : Gredos, 1969.

BIARD, J., Logique et théorie du signe au XIV siècle. Paris: 2. ed. Vrin, 2006 (Original de 1989).

. La conception cartésienne de l'étendue et les débats médiévaux sur la quantité. In: BIARD, J.; RASHED, R. (Ed.). Descartes et le Moyen Âge. Paris: Vrin, 1997, p. 349-361. .; RASHED, R. (Ed.). Descartes et le Moyen Âge. Paris: Vrin, 1997.

BOEHNER, P. Ockham's Philosophy in the light of the recent research. In:

Collected Articles On Ockham. Edited by Eligius M. Buytaert, O.F.M. Nova Iorque: The Franciscan Institute, 1958a, p. 23-28. (Originalmente publicado em 1948). 
The text tradition of Ockham's Ordinatio. In: Collected Articles On Ockham. Edited by Eligius M. Buytaert, O.F.M. Nova Iorque: The Franciscan Institute, 1958b, p. 110-127. (Originalmente publicado em 1942).

A Recent Presentation of Ockham's Philosophy. In: Collected Articles On Ockham. Edited by Eligius M. Buytaert, O.F.M. Nova Iorque: The Franciscan Institute, 1958c, p. 136-156. (Originalmente publicado em 1949).

BOTTIN, F. La scienza degli occamisti - la scienza tardo-medievale dalle origini del paradigma nominalista alla rivoluzione scientifica. Bolonha: Rimini, 1982.

COURTINE, J.-F. Suarez et le système de la métaphysique. Paris: PUF, 1990.

DROIT, R.-P. Un cataclysme nommé Ockham. Le Monde, 10 Février 1989.

GABBEY, A. "Pondere, numero et mensura " Roberval et la géometrie divine. Revue de synthèse: $4^{\mathrm{e}}$ ser., $\mathrm{n}^{\mathrm{os}}$ 2-3-4, p. 521-529, avr.-déc. 2001.

GINZBURG, C. O alto e o baixo: O tema do conhecimento proibido nos séculos XVI e XVII. In: _. Mitos, Emblemas, Sinais: Morfologia e História. Tradução de Federico Carotti. 2. ed. São Paulo: Companhia das Letras, 2003, p. 95-117 (Original de 1986).

GODDU, A. The Physics of William of Ockham. Leiden: Brill, 1984.

Ockham's Philosophy of Nature. In: SPADE, P. V. (Org.). The Cambridge Companion to Ockham. Cambridge: UP, 1999, p. 143-167.

HEDWIG, K. Roger Bacon - Scientia experimentalis. In KOBUSCH, Th. (Org.). Filósofos da Idade Média. Uma introdução. 2. reimpr.Tradução de Paulo Astor Soethe. São Leopoldo: Unisinos, 2005, p. 189-205.

KÖNIG-PRALONG, C. Avènement de l'aristotélisme en terre chrétienne. L'essence et la matière: entre Thomas d'Aquin et Guillaume d'Ockham. Paris: Vrin, 2005.

KOYRÉ, A. As origens da ciência moderna: uma nova interpretação. In: ___. Estudos de História do Pensamento Científico. Tradução e Revisão Técnica de Márcio Ramalho. Rio de Janeiro: Forense-Universitária/UnB, 1982a, p. 56-80. (Originalmente publicado em 1956).

Galileu e Platão.. In: Estudos de História do Pensamento Cientifico.

Tradução e Revisão Técnica de Márcio Ramalho. Rio de Janeiro: Forense-Universitária/ UnB, 1982b, p. 152-180. (Originalmente publicado em 1943).

Galileu e a Revolução Científica do Século XVII. In: KOYRÉ, A. Estudos de História do Pensamento Científico. Traduçáo e Revisão Técnica de Márcio Ramalho. Rio de Janeiro: Forense-Universitária/UnB, 1982c, p. 181-196. (Originalmente publicado em 1943.

. Leonardo Da Vinci 500 anos depois.KOYRÉ, A. Estudos de História do Pensamento Científico. Tradução e Revisão Técnica de Márcio Ramalho. Rio de Janeiro: ForenseUniversitária/UnB, 1982d, p. 91-106. (Originalmente publicado em 1953).

LARRE, O. La filosofía natural de Ockham. Una fenomenología del individuo. Pamplona: Eunsa, 2000. 
LIBERA, A. de. A Filosofia Medieval. Tradução de Nicolás Nyimi Campanário e Yvone Maria de Campos Teixeira da Silva. São Paulo: São Paulo : Loyola, 1998 (Original de 1993).

. La Querelle des universaux. De Platon à la fin du Moyen Âge. Paris: Seuil, 1996.

Pensar na Idade Média. Tradução de Paulo Neves. São Paulo: Ed. 34, 1999 (Original de 1991).

Raison et Foi. Archéologie d'une crise d'Albert le Grand à Jean-Paul II. Paris: Seuill, 2003.

NASCimentO, C. A. R. do. De Tomás de Aquino a Galileu. Coleçâo Trajetória 2. Campinas: Unicamp/IFCH, 1995.

PANZA, M. La Révolution Scientifique, les Révolutions et l'Histoire des Sciences: comment Ernest Coumet nous a libérés de l'héritage d'Alexandre Koyré. Revue de synthèse: $4^{\mathrm{e}}$ ser., $\mathrm{n}^{\text {os }} 2-3-4$, p. 411-424, avr.-déc. 2001.

PERINI-SANTOS, E. La théorie ockhamienne de la connaissance évidente. Paris: Vrin, 2006.

PERLER, D. Descartes, critique de la théorie médiévale des species. In: BIARD, J.; RASHED, R. (Ed.). Descartes et le Moyen Âge. Paris: Vrin, 1997, p. 141-153.

RENAULT, L. Descartes et les théories médiévales de l'abstraction. Quelques points de repères. In: BIARD, J.; RASHED, R. (Ed.). Descartes et le Moyen Âge. Paris: Vrin, 1997, p. 199-214.

ROBINET, A. Dialectiques et regulae: lieux et concepts. In: BIARD, J.; RASHED, R. (Ed.). Descartes et le Moyen Âge. Paris: Vrin, 1997, p. 231-240.

ROSSI, P., A ciência e a filosofia dos modernos. Tradução de Álvaro Lorencini. São Paulo: UNESP, 1992, 1a reimpressão (Original de 1988).

Da magia à ciência. Tradução: Aurora Fornoni Bernardini. Londrina/Curitiba: Eduel/UFPR, 2006 (Originalmente publicado em 1957).

. I filosofi e le macchine (1400/1700). Milão: Feltrinelli, 1962.

SPADE, P. V. (Org.), The Cambridge Companion to Ockham. Cambridge: UP, 1999.

recebido em: 07.05.2011

aprovado em: 14.9.2011 